\title{
IDENTIFIKASI KEBUTUHAN PENGGUNA KURSI SANDAR DI PERON STASIUN
}

\author{
Identification of User Needs Recliner Chair on The Platform of The Station \\ Nurjannah ${ }^{1 *}$ dan Eko Putri Hadi Winarsih ${ }^{1}$ \\ ${ }^{1}$ Teknik Industri Universitas Gunadarma, Jl. Margonda Raya No. 100, Jawa Barat, Indonesia
}

\section{Informasi artikel \\ Diterima: 10/05/2019 Direvisi : 20/05/2019 Disetujui: 20/05/2019}

\begin{abstract}
Abstrak
Kursi sandar merupakan kursi tunggu yang disiapkan oleh PT. Kereta Commuter Indonesia (PT. $\mathrm{KCl}$ ) disetiap peron stasiun. Pergantian bentuk kursi sandar dinilai tidak memberikan rasa nyaman bagi para penumpang, oleh karena perlu diidentifikasi kebutuhan kursi sandar penumpang dengan menggunakan metode Quality Function Deployment (QFD). Metode QFD merupakan suatu metode yang terstruktur didalam pengembangan produk yang memungkinkan tim pengembangan produk untuk menetapkan dengan jelas semua keinginan dan kebutuhan konsumen. Data dalam penelitian ini merupakan data primer yang didapatkan dari penyebaran kuesioner dan wawancara kepada pengguna commuter line khususnya yang menggunakan stasiun Manggarai dan stasiun Jatinegara. Pengambilan data melibatkan 100 orang pengguna commuter line yang diambil secara acak (random sampling). Berdasarkan metode QFD didapatkan kebutuhan pelanggan prioritas dari kursi sandar yaitu nyaman saat digunakan, aman untuk digunakan, tidak mudah rusak, dan mampu menahan beban. Karakteristik teknis prioritas yaitu ukuran tinggi dudukan dan jenis material yang digunakan pada kursi sandar. Perbaikan kursi sandar antara lain mengganti ukuran tinggi kursi, ukuran tinggi dudukan kursi, tinggi sandaran kursi, dan banyaknya jumlah kursi di peron stasiun.
\end{abstract}

Kata Kunci: commuter line, kebutuhan pengguna, kursi sandar.

\begin{abstract}
Recliner Chair is a waiting chair prepared by the PT. Kereta Commuter Indonesia $(P T . K C l)$ at each station platform. The replacement of the seat recliner shape is assessed not provide comfort for the passengers, therefore need to be identified passenger recliner Chair needs using Quality Function Deployment (QFD). QFD method is a method that is structured in product development that allows the product development team to establish clearly all the wants and needs of consumers. The data in this study is the primary data obtained from the dissemination of a questionnaire and interviews to users who use a commuter line in Manggarai station and Jatinegara station. Data retrieval involves 100 people user commuter line taken at random (random sampling). Based on QFD method obtained priority customer requirements from the seat recliner that is comfortable when used, safe to use, not easily broken, and able to withstand the load. Technical characteristics size i.e. high priority seat and the type of material used on the recliner chair. Repair chair recliner among others resize high chair, high chair holder size, high chair, and a large number of seats on the platform of the station.
\end{abstract}

Keywords: filing system, incoming mail and outgoing mail, PHP, Mysql

*Penulis Korespondensi : Handphone: - 


\section{PENDAHULUAN}

Kereta api merupakan salah satu moda transportasi umum yang digunakan penumpang. Kereta api dipilih karena waktu tempuh yang lebih singkat dibandingkan dengan moda transportasi lainnya. salah satu jenis kereta api yang sering digunakan yaitu Kereta Api Commuter Jabodetabek atau disebut juga KRL Commuter Line. Commuter line adalah kereta rel listrik yang dioperasikan oleh PT Kereta Api Commuter Indonesia (PT. KCl), anak perusahaan dari PT Kereta Api Indonesia (PT. KAI). KRL telah beroperasi sejak tahun 1976, hingga kini melayani rute di wilayah DKI Jakarta, Kota Depok, Kota Bogor, Kabupaten Bogor, Kota Bekasi, Kabupaten Lebak, Kota Tangerang, dan Kota Tangerang Selatan. Salah satu stasiun transit yang berada pada Daerah Operasi (DAOP) 1 Jabodetabek adalah Stasiun Manggarai yang rata-rata dikunjungi 800.000 penumpang per hari (Putra, 2016).

Seiring bertambahnya jumlah penumpang commuter line, pihak jasa PT. $\mathrm{KCl}$ mem-persiapkan berbagai strategi dan fasilitas pelayanan, seperti penambahan jumlah KRL untuk menampung banyaknya penumpang agar mempersingkat waktu tunggu penumpang. Selain penambahan jumlah KRL, pihak jasa tersebut mempersiapkan fasilitas untuk menunggu kedatangan kereta yaitu kursi tunggu yang terletak diperon kereta. Kursi tunggu pada tahun ini mengalami perubahan dan perbaikan menjadi kursi sandar guna lebih meningkatkan pelayanan. Kursi tunggu jenis baru yang dihadirkan memiliki tujuan untuk mengefisienkan ruang tunggu peron dan membuat kursi yang ergonomis (Wardani, 2015).

Menurut pihak kereta api dalam beberapa wawancara di media, pergantian kursi sandar merupakan rancangan dari hasil evaluasi penggunaan kursi tunggu demi kenyamanan bersama. Akan tetapi, penyediaan kursi sandar pada beberapa stasiun transit tidak diinginkan oleh sebagian penumpang pada saat menunggu kereta berikutnya. Kursi sandar dinilai tidak memberikan rasa nyaman serta tidak mengurangi rasa kelelahan pada saat menunggu. Stasiun manggarai merupakan salah satu stasiun transit yang telah mengganti semua kursi tunggu menggunakan kursi sandar jenis baru. Penumpang yang berada distasiun manggarai merasa tidak nyaman dengan penggunaan kursi sandar (Kusuma, 2015).
Kepuasan pelanggan merupakan salah satu kunci suksesnya sebuah rancangan produk yang sesuai dengan desain industri yang dibuat dan kualitas yang baik. Kualitas merupakan suatu kondisi dinamis yang berhubungan dengan produk, jasa, manusia, proses dan lingkungan yang memenuhi atau melebihi harapan. Pendapat tersebut dapat dimaksudkan bahwa seberapa besar kualitas yang diberikan yang berhubungan dengan produk barang beserta faktor pendukungnya memenuhi harapan penggunanya. Dapat diartikan bahwa semakin memenuhi harapan konsumen, maka produk tersebut semakin berkualitas (Tjiptono, 2008).

Kualitas produk merupakan kemampuan sebuah produk dalam menampilkan fungsinya baik dalam sudut pandang internal maupun sudut pandang eksternal. Hal ini termasuk keseluruhan daya tahan dari produk, keandalan, ketepatan, presisi, kemudahan, pengoperasian dan perbaikan produk, juga atribut produk lainnya (Kotler, 2006). Oleh karena itu penelitian dan analisa suatu rancangan dalam penelitian ini menggunakan metode Quality Function Deployment (QFD). Quality function deployment (QFD) merupakan suatu metode yang terstruktur didalam pengembangan produk yang memungkinkan tim pengembangan produk untuk menetapkan dengan jelas semua keinginan dan kebutuhan konsumen. Tujuan dari quality function deployment tidak hanya memenuhi kebutuhan konsumen, tetapi juga berusaha melampaui harapan-harapan konsumen sebagai cara untuk berkompetensi dengan saingannya, sehingga diharapkan konsumen tidak menolak, tetapi malah menginginkan produk atau jasa tersebut (Cohen, 1995).

Tujuan dari penelitian ini yaitu untuk mengidentifikasi kebutuhan pengguna kursi sandar di peron stasiun, selain itu mengetahui karakteristik teknis dominan untuk pengembangan kursi sandar. Tujuan lainnya yaitu memberikan usulan perbaikan berdasarkan kebutuhan pengguna dan karakteristik rancangan produk.

\section{METODOLOGI}

Berikut merupakan metodologi peelitian yang digunakan yang ditampilkan pada gambar 1, yaiu diagram alir penelitian. Terdiri dari 4 (empat) tahapan utama dalam melakukan identifiasi kasus atau persoalan yang akan diselesaikan. 
Pengumpulan Data

1. Kebutuhan Pengguna

Data Primer: Kuesioner dan wawancara

2. Karakteristik teknis \& Spesifikasi Produk Data Sekunder: Hasil Penelitian Sebelumnya dan studi pustaka

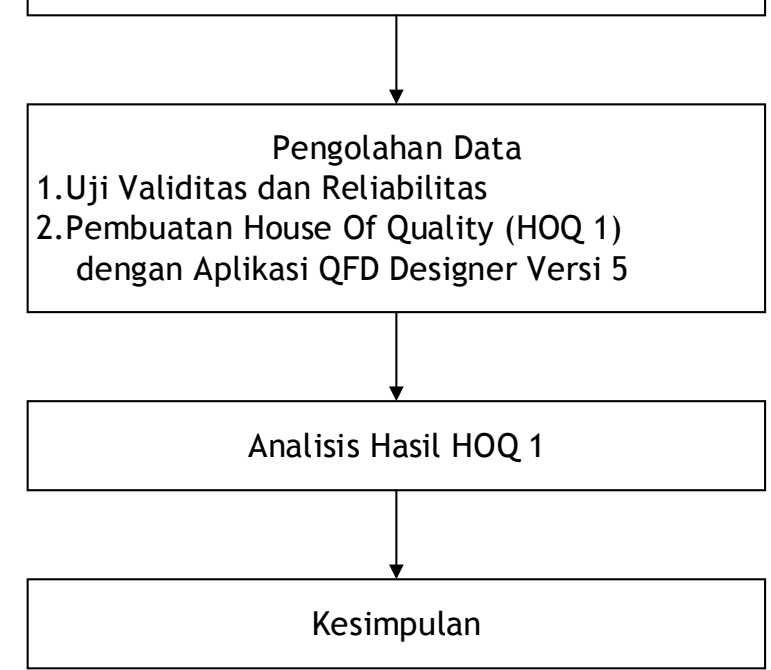

Gambar 1 Diagram Alir Penelitian

\section{Pengumpulan Data}

Subjek penelitian yaitu pengguna commuter line khususnya yang melakukan transit pada stasiun Manggarai dan stasiun Jatinegara. Penentuan kebutuhan pengguna kursi sandar menggunakan data primer berupa wawancara dan penyebaran kuesioner kepada subjek penelitian. Jumlah sampel yang digunakan dalam penelitian ini dihitung dengan menggunakan jumlah ukuran sampel bagi pendugaan $\mu$ (Walpole, 1992).

$$
n=\frac{Z^{2} \alpha / 2}{4 e^{2}}
$$

Keterangan:

$$
\begin{aligned}
\mathrm{n}= & \text { ukuran sampel } \\
\mathrm{a}= & \text { taraf nyata, yang diperoleh dari } \\
& \text { tingkat kepercayaan yang } \\
& \text { digunakan dengan persamaan (1- } \\
& \mathrm{a}) 100 \% \\
& \text { nilai } \mathrm{z} \text { pada kurva normal } \\
& \text { berdasarkan taraf nyata yang } \\
\mathrm{Z}^{2} \alpha / 2= & \text { digunakan } \\
\mathrm{e}= & \text { tingkat ketelitian yang digunakan }
\end{aligned}
$$

Berdasarkan teknik pengambilan sampel diatas, peneliti perlu melakukan penetapan pada tingkat kepercayaan dan tingkat ketelitian untuk pengambilan sampel pengguna kereta api. Peneliti menggunakan tingkat kepercayaan sebesar $95 \%$ dan tingkat ketelitian sebesar $5 \%$. Hasil dari perhitungan yang digunakan penelitian berdasarkan ketentuan guna menentukan jumlah sampel yaitu:

$$
\begin{array}{ll}
a & =100 \%-95 \%=5 \% \\
\alpha / 2 & =\frac{5 \%}{2}=2,5 \%=0,025 \\
Z_{0,025}= & 1,96(\text { Berdasarkan tabel) } \\
\mathrm{e} & =5 \% \\
n & =\frac{(1,96)^{2}}{4(0,05)^{2}} \\
& =96,05 \approx 100 \text { orang }
\end{array}
$$

Jumlah responden yang dikatakan mencukupi untuk penelitian ini yaitu 97 orang. Peneliti meminimalisir sebuah kesalahan yang ada dilapangan ketika penelitian sehingga, melakukan penyebaran kuesioner sebanyak 100 orang. Pengambilan responden dilakukan secara acak (random sampling) pada para pengguna commuter line yang transit distasiun Manggarai dan Jatinegara yang sedang ataupun pernah menggunakan kursi sandar yang terletak di peron stasiun. Stasiun Manggarai merupakan stasiun utama penelitian, dimana pada stasiun ini keseluruhan fasilitas kursi tunggu sudah terganti oleh kursi sandar jenis baru. Sedangkan, pada stasiun pembanding yaitu stasiun Jatinegara kursi tunggu yang disediakan belum terdapat kursi sandar.

Setelah mendapatkan kebutuhan pengguna kursi sandar selanjutnya melakukan pengumpulan data terkait karakteristik teknis, spesifikasi produk kursi sandar sebelumnya, dan target perubahan. Spesifikasi dan karakteristik teknis didapatkan berdasarkan data sekunder yaitu hasil penelitian sebelumnya dan studi pustaka.

\section{Pengolahan Data}

Pengolahan data dilakukan apabila keseluruhan data yang dibutuhkan telah tercukupi dan melalui proses penyaringan. Penyaringan dimulai dengan mengidentifikasi identitas pelanggan atau sampel dan menjabarkan kembali secara detail hasil kuesioner yang disebarkan. Pengolahan data yang pertama dilakukan oleh peneliti yaitu melihat sejauh mana keakuratan dan konsistensi data. Kecukupan data pada kuesioner akan melalui proses uji validitas dan uji realibilitas.

Pengujian validitas diperlukan untuk menyatakan sejauh mana data yang ditampung pada suatu kuesioner akan mengukur apa yang ingin diukur (Umar, 2003).Validitas berhubungan dengan kenyataan dan tujuan pengukuran. 
Pengukuraan dikatakan valid jika tujuannya nyata dan benar, tidak valid artinya memberikan hasil ukuran menyimpang dari tujuan. Suatu instrumen dinyatakan valid jika nilai $r$ hitung $>r$ tabel. Rumus Bivariate Pearson adalah (Jogiyanto, 2008):

$$
r_{X Y}=\frac{N \sum X Y-\sum X \sum Y}{\sqrt{\left(N \sum X^{2}-\left(\sum X\right)^{2}\right)\left(N \sum Y^{2}-\left(\sum Y\right)^{2}\right)}}
$$

Keterangan:

$$
\begin{aligned}
& r_{x y}=\text { koefisien korelasi } \\
& Y=\text { skor total } \\
& X=\text { skor pertanyaan } \\
& N=\text { banyaknya subjek }
\end{aligned}
$$

Pengujian reliabilitas diperlukan untuk menunjukkan sejauh mana suatu hasil pengukuran konsisten jika alat ukur yang digunakan berulang kali (Umar, 2003). Relibilitas menunjukkan akurasi dan konsistensi dari pengukurnya. Konsisten artinya pengukuran yang dilakukan berulangkali terhadap suatu subjek yang sama didapatkan hasil yang tidak berbeda. Reliabilitas dapat diukur dengan Cronbach's Alpha. Jika nilai Cronbach's Alpha mendekati 1 maka reliabilitasnya semakin tinggi. Umumnya nilai reliabilitas adalah $>0,6$. Rumus dari Cronbach's Alpha (Jogiyanto, 2008):

$$
\alpha=\frac{\mathrm{k}}{\mathrm{k}-1}=1-\frac{\sum \alpha^{2} \mathrm{xi}}{\alpha \mathrm{x}^{2}}
$$

Pengolahan data selanjutnya yaitu membuat House of Quality 1 (HOQ 1) menggunakan aplikasi QFD Designer versi 5. Aplikasi ini merupakan rancangan rumah kualitas secara visual yang didapatkan setelah melakukan urutan langkah menggunakan metode QFD.

\section{HASIL DAN PEMBAHASAN}

\section{Atribut Kebutuhan Pengguna}

Atribut keinginan pengguna jasa berisikan variabel yang diinginkan oleh pengguna jasa berdasarkan kuesioner pendahuluan. Hasil dari kuesioner pendahuluan melalui penyaringan dan diterjemahkan menjadi atribut keinginan pengguna kursi.

Hasil dari uji validitas menggunakan nilai korelasi (pearson correlation) harus

\begin{tabular}{|c|c|c|}
\hline \multicolumn{3}{|c|}{ Atribut Keinginan Pengguna Jasa } \\
\hline Primer & Sekunder & Tersier \\
\hline \multirow{6}{*}{$\begin{array}{l}\text { Keinginan } \\
\text { Pengguna } \\
\text { Kursi } \\
\text { Sandar }\end{array}$} & Performance & $\begin{array}{l}\text { Kursi sandar } \\
\text { memberikan } \\
\text { kenyamanan } \\
\text { Kursi sandar aman } \\
\text { untuk digunakan }\end{array}$ \\
\hline & Conformance & $\begin{array}{l}\text { Kursi sandar dapat } \\
\text { digunakan segala usia } \\
\text { Kursi sandar mampu } \\
\text { memuat banyak } \\
\text { beban }\end{array}$ \\
\hline & & $\begin{array}{l}\text { Kursi sandar tidak } \\
\text { mudah rusak }\end{array}$ \\
\hline & Durability & $\begin{array}{l}\text { Kursi sandar tidak } \\
\text { mudah berkarat }\end{array}$ \\
\hline & & $\begin{array}{l}\text { Kursi sandar mampu } \\
\text { menahan beban }\end{array}$ \\
\hline & Aesthetic & $\begin{array}{l}\text { Kursi sandar memiliki } \\
\text { desain yang inovasi } \\
\text { dan variasi } \\
\text { Kursi sandar memiliki } \\
\text { desain yang menarik }\end{array}$ \\
\hline
\end{tabular}
memiliki nilai lebih besar $>$ dari nilai table $r$ dengan nilai tingkat kepercayaan sebesar $5 \%$ yaitu 0,195 . Hasil uji validitas dapat dilihat pada Tabel 2.

Tabel 1 Atribut keinginan pengguna jasa

Tabel 2 Hasil uji validitas

\begin{tabular}{ccccc}
\hline $\begin{array}{c}\text { Korelasi } \\
\text { Antara }\end{array}$ & $\begin{array}{c}\text { Nilai } \\
\text { Korelas } \\
\text { Atribut }\end{array}$ & $\begin{array}{c}\text { Nilai } \\
\text { Tabel r } \\
(\mathrm{n}=100, \\
\mathrm{a}=5 \%)\end{array}$ & $\begin{array}{c}\text { sig. (2- } \\
\text { tailed) }\end{array}$ & $\begin{array}{c}\text { Kesimp } \\
\text { ulan }\end{array}$ \\
\hline Atribut 1 & 0,875 & & 0,00 & Valid \\
Atribut 2 & 0,835 & & 0,00 & Valid \\
Atribut 3 & 0,825 & & 0,00 & Valid \\
Atribut 4 & 0,723 & 0,195 & 0,00 & Valid \\
Atribut 5 & 0,861 & & 0,00 & Valid \\
Atribut 6 & 0,891 & & 0,00 & Valid \\
Atribut 7 & 0,865 & & 0,00 & Valid \\
Atribut 8 & 0,756 & & 0,00 & Valid \\
Atribut 9 & 0,785 & & 0,00 & Valid \\
\hline
\end{tabular}

Hasil uji validitas menunjukkan bahwa dari atribut dari kuesioner menyatakan bahwa nilai tersebut valid untuk memiliki korelasi. Selanjutnya melakukan pengujian reliabilitas dilakukan untuk mengetahui tingkat konsistensi atribut. Berikut Gambar 2 merupakan hasil keluaran software untuk mengetahui reliabilitas data. 
Reliability Statistics

\begin{tabular}{|r|r|}
\hline $\begin{array}{c}\text { Cronbach's } \\
\text { Alpha }\end{array}$ & N of Items \\
\hline .940 & 9 \\
\hline
\end{tabular}

Gambar 2 Hasil keluaran uji reliabilitas

Nilai Cronbach Alpha pada data kuesioner kebutuhan pengguna jasa didapatkan hasil pengolahan software SPSS 16.0 sebesar $0,940>0,6$, sehingga dapat dikatakan reliabel dari data kuesioner.

\section{Prioritas Kebutuhan Pengguna}

Data kuesioner penilaian terhadap tingkat kepentingan berbentuk kuesioner tertutup. Kuesioner tertutup memudahkan pengguna jasa untuk memilih jawaban pada atribut produk dengan menggunakan skala prioritas atau skala likert. Skala likert memiliki ketentuan skala prioritas dari bobot 5 keterangan sangat penting, bobot 4 keterangan penting, bobot 3 keterangan kurang penting, bobot 2 keterangan tidak penting dan bobot 1 keterangan sangat tidak penting.

Berdasarkan hasil penyebaran kebutuhan pengguna jasa, responden sangat selektif dan mempertimbangkan kebutuhan dari segala aspek. Tingkat kepentingan konsumen dihitung berdasarkan rata-rata pilihan responden dengan memilih tingkat kepentingan atribut produk kursi sandar. Pada Tabel 3 akan memperlihatkan tingkat kepentingan atribut kursi sandar.

\section{Karakteristik Teknis}

Karakteristik teknis menjelaskan secara detail keinginan pengguna jasa kedalam bentuk teknis. Karakteristik teknis melalui penentuan faktor karakteristik dari mulai dalam bentuk sekunder hingga diterjemahkan kembali kedalam bentuk tersier. Karakteristik teknis terdapat satuan hitung yang digunakan pada masing-masing karakteristik. Tabel 4 merupakan penjabaran detail karakteristik teknis yang ditentukan pada produk kursi sandar.
Tabel 3 Tingkat kepentingan atribut kursi sandar

\begin{tabular}{|c|c|c|c|}
\hline No. & Primer & Pertanyaan & $\begin{array}{c}\text { Tingkat } \\
\text { Kepentingan }\end{array}$ \\
\hline 1. & & $\begin{array}{l}\text { Kursi sandar } \\
\text { memberikan } \\
\text { kenyamanan }\end{array}$ & 5 \\
\hline 2. & & $\begin{array}{l}\text { Kursi sandar } \\
\text { aman untuk } \\
\text { digunakan } \\
\text { Kursi sandar }\end{array}$ & 5 \\
\hline 3. & & $\begin{array}{l}\text { dapat digunakan } \\
\text { segala usia }\end{array}$ & 4 \\
\hline 4. & & $\begin{array}{l}\text { Kursi sandar } \\
\text { mampu memuat } \\
\text { banyak beban }\end{array}$ & 4 \\
\hline 5. & $\begin{array}{c}\text { Keinginan } \\
\text { Pengguna } \\
\text { Kursi } \\
\text { Sandar }\end{array}$ & $\begin{array}{l}\text { Kursi sandar } \\
\text { tidak mudah } \\
\text { rusak }\end{array}$ & 5 \\
\hline 6. & & $\begin{array}{l}\text { Kursi sandar } \\
\text { tidak mudah } \\
\text { berkarat }\end{array}$ & 4 \\
\hline 7. & & $\begin{array}{l}\text { Kursi sandar } \\
\text { mampu menahan } \\
\text { beban }\end{array}$ & 5 \\
\hline 8. & & $\begin{array}{l}\text { Kursi sandar } \\
\text { memiliki desain } \\
\text { yang inovasi dan } \\
\text { variasi }\end{array}$ & 4 \\
\hline 9. & & $\begin{array}{l}\text { Kursi sandar } \\
\text { memiliki desain } \\
\text { yang menarik }\end{array}$ & 3 \\
\hline
\end{tabular}

Tabel 4 Karakteristik teknis kursi sandar

\begin{tabular}{|c|c|c|c|}
\hline \multicolumn{4}{|c|}{ Karakteristik Teknis } \\
\hline Primer & Sekunder & Tersier & Satuan \\
\hline \multirow{18}{*}{$\begin{array}{c}\text { Karakteristik } \\
\text { Teknis }\end{array}$} & \multirow{16}{*}{$\begin{array}{l}\text { Dimensi } \\
\text { Produk }\end{array}$} & Ukuran lebar kursi & $\mathrm{Cm}$ \\
\hline & & Ukuran tinggi kursi & $\mathrm{Cm}$ \\
\hline & & Ukuran kedalaman & $\mathrm{Cm}$ \\
\hline & & kursi & \\
\hline & & Ukuran pembatas & $\mathrm{Cm}$ \\
\hline & & kursi & \\
\hline & & Ukuran tinggi & $\mathrm{Cm}$ \\
\hline & & dudukan kursi & \\
\hline & & Ukuran tinggi & $\mathrm{Cm}$ \\
\hline & & sandaran kursi & \\
\hline & & Derajat & $\left({ }^{\circ}\right)$ \\
\hline & & kemiringan & \\
\hline & & sandaran & \\
\hline & & Jumlah komponen & Unit \\
\hline & & kursi & \\
\hline & & Jumlah kaki kursi & Unit \\
\hline & \multirow{2}{*}{ Material } & Jenis material & Subject \\
\hline & & Diameter material & $\mathrm{Cm}$ \\
\hline
\end{tabular}




\section{Spesifikasi Produk}

Produk yang dihasilkan memiliki spesifikasi tertentu berdasarkan wujud, fungsi dan tujuan perancangan. Spesifikasi produk merupakan rincian atau uraian keterangan dari produk. Kursi sandar memiliki spesifikasi produk yang mengarah kepada pemakaian serta bentuk dari produk. Tabel 5 merupakan spesifikasi produk dari kursi sandar yang sudah ada diperon stasiun Manggarai.

Tabel 5 Spesifikasi produk kursi sandar

\begin{tabular}{clc}
\hline No. & \multicolumn{1}{c}{ Spesifikasi } & $\begin{array}{c}\text { Keterangan } \\
\text { Produk }\end{array}$ \\
\hline 1. & $\begin{array}{l}\text { Panjang besi kursi } \\
\text { sandar }\end{array}$ & $220 \mathrm{~cm}$ \\
2. & $\begin{array}{l}\text { Tinggi kursi sandar } \\
\text { 3. }\end{array}$ & $\begin{array}{l}\text { Tinggi sandaran kursi } \\
\text { sandar }\end{array}$ \\
4. & $76 \mathrm{~cm}$ \\
Jumlah kaki kursi & 2 unit \\
5. $\begin{array}{l}\text { Jumdar } \\
\text { kursi sandar komponen }\end{array}$ & 7 unit besi \\
6. & $\begin{array}{l}\text { Material kursi sandar } \\
\text { Jumlah muatan orang }\end{array}$ & $\begin{array}{c}\text { Steinless steel } \\
4 \text { orang }\end{array}$ \\
\hline
\end{tabular}

Gambar 3 merupakan gambar kursi sandar yang berada di peron stasiun Manggarai.

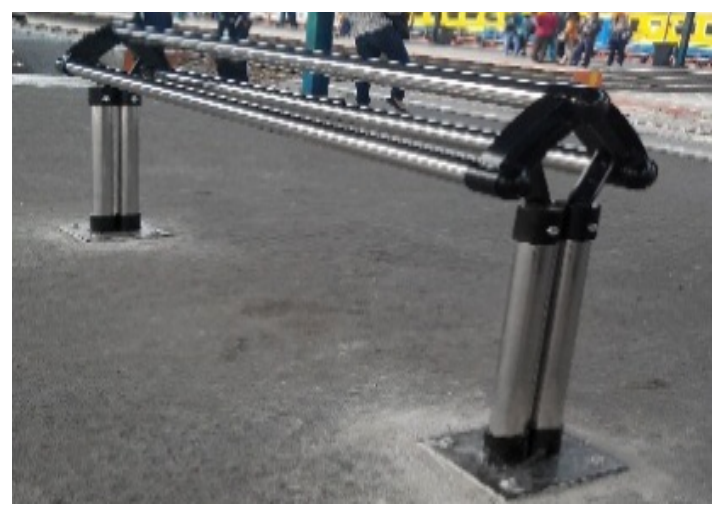

Gambar 3 Kursi sandar di peron stasiun manggarai

\section{Target Perbaikan}

Target perbaikan merupakan rencana perbaikan dari produk yang tidak memberikan rasa puas pada saat pemakaian. Perbaikan dilakukan apabila terdapat sisi kekurangan dari produk yang dihasilkan. Berdasarkan penelitian, pengguna jasa kereta merasakan secara langsung fungsi dari kursi sandar yang dirasa masih kurang dalam hal pemenuhan keinginan dan kebutuhan pengguna. Target perbaikan melihat dari sumber terbaik rancangan produk yang tepat berdasarkan nilai ergonomis suatu produk serta ukuran antropometri yang sesuai. Target perbaikan dapat dilihat secara jelas pada Tabel 6.

Tabel 6 Target perbaikan kursi

\begin{tabular}{|c|c|c|c|}
\hline \multirow[b]{2}{*}{ No. } & \multirow[b]{2}{*}{ Karakteristik } & \multicolumn{2}{|c|}{ Kondisi Produk } \\
\hline & & Saat Ini & $\begin{array}{c}\text { Target } \\
\text { Perbaikan }\end{array}$ \\
\hline 1. & $\begin{array}{l}\text { Ukuran lebar } \\
\text { kursi }\end{array}$ & $220 \mathrm{~cm}$ & $220 \mathrm{~cm}$ \\
\hline 2. & $\begin{array}{l}\text { Ukuran tinggi } \\
\text { kursi }\end{array}$ & $87 \mathrm{~cm}$ & $107,1 \mathrm{~cm}$ \\
\hline 3. & $\begin{array}{l}\text { Ukuran } \\
\text { kedalaman } \\
\text { kursi }\end{array}$ & $20,29 \mathrm{~cm}$ & $20,99 \mathrm{~cm}$ \\
\hline 4. & $\begin{array}{l}\text { Ukuran } \\
\text { pembatas kursi }\end{array}$ & $6,4 \mathrm{~cm}$ & $6,4 \mathrm{~cm}$ \\
\hline 5. & $\begin{array}{l}\text { Ukuran tinggi } \\
\text { dudukan kursi }\end{array}$ & $76 \mathrm{~cm}$ & $44,59 \mathrm{~cm}$ \\
\hline 6. & $\begin{array}{l}\text { Ukuran tinggi } \\
\text { sandaran kursi }\end{array}$ & $87 \mathrm{~cm}$ & $170 \mathrm{~cm}$ \\
\hline 7. & $\begin{array}{l}\text { Derajat } \\
\text { kemiringan } \\
\text { sandaran }\end{array}$ & $90^{\circ}$ & $90^{\circ}$ \\
\hline 8. & $\begin{array}{l}\text { Jumlah } \\
\text { komponen kursi }\end{array}$ & 7 unit & 10 unit \\
\hline 9. & $\begin{array}{l}\text { Jumlah kaki } \\
\text { kursi }\end{array}$ & 2 kaki & 2 kaki \\
\hline 10. & Jenis material & $\begin{array}{l}\text { Stainless } \\
\text { steel }\end{array}$ & $\begin{array}{l}\text { Stainless } \\
\text { steel }\end{array}$ \\
\hline 11. & $\begin{array}{l}\text { Diameter } \\
\text { material }\end{array}$ & $6.4 \mathrm{~cm}$ & $6,4 \mathrm{~cm}$ \\
\hline
\end{tabular}

Gambar 4 merupakan rancangan dari target perbaikan.

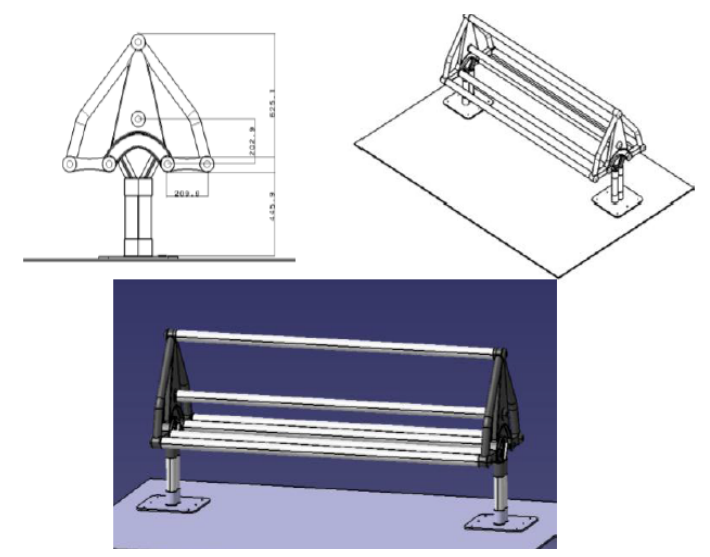

Gambar 4 Usulan target perbaikan

\section{Benchmarking}

Benchmarking terdiri dari pembuatan customer assessment dan technical assessment. Customer assessment merupakan pembentukkan suatu penilaian terhadap posisi produk yang diteliti dengan produk pembanding. 
Customer yang diminta untuk mengisi kuesioner ini yaitu para pengguna commuter line yang pernah menggunakan kedua stasiun yaitu stasiun Manggarai dan stasiun Jatinegara.

Tabel 7 Perbandingan customer assessment

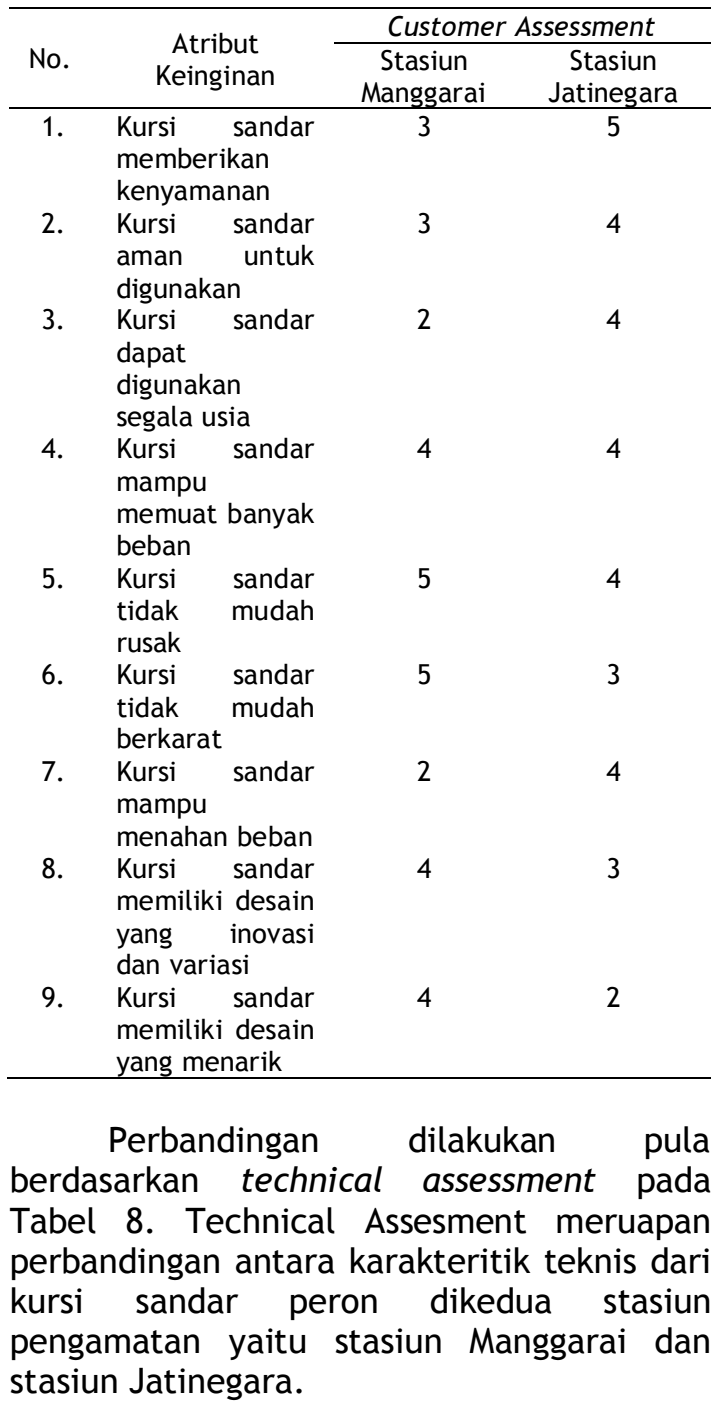

HOQ 1

Pembentukkan House of Quality 1 (HOQ 1) merupakan gambaran rumah kualitas berdasarkan keseluruhan tahapan sebelumnya. Berikut ini merupakan hasil pembentukkan house of quality 1 pada Gambar 5.
Tabel 8 Perbandingan Technical Assessment

\begin{tabular}{|c|c|c|c|}
\hline \multirow[b]{2}{*}{ No. } & \multirow[b]{2}{*}{$\begin{array}{c}\text { Karakteristik } \\
\text { Teknis }\end{array}$} & \multicolumn{2}{|c|}{ Technical Assessment } \\
\hline & & $\begin{array}{c}\text { Stasiun } \\
\text { Manggarai }\end{array}$ & $\begin{array}{c}\text { Stasiun } \\
\text { Jatinegara }\end{array}$ \\
\hline 1. & $\begin{array}{l}\text { Ukuran lebar } \\
\text { kursi }\end{array}$ & 4 & 4 \\
\hline 2. & $\begin{array}{l}\text { Ukuran tinggi } \\
\text { kursi }\end{array}$ & 3 & 4 \\
\hline 3. & $\begin{array}{l}\text { Ukuran } \\
\text { kedalaman kursi }\end{array}$ & 2 & 4 \\
\hline 4. & $\begin{array}{l}\text { Ukuran } \\
\text { pembatas kursi }\end{array}$ & 3 & 4 \\
\hline 5. & $\begin{array}{l}\text { Ukuran tinggi } \\
\text { dudukan kursi }\end{array}$ & 2 & 5 \\
\hline 6. & $\begin{array}{l}\text { Ukuran tinggi } \\
\text { sandaran kursi }\end{array}$ & 3 & 4 \\
\hline 7. & $\begin{array}{l}\text { Derajat } \\
\text { kemiringan } \\
\text { sandaran }\end{array}$ & 3 & 4 \\
\hline 8. & $\begin{array}{l}\text { Jumlah } \\
\text { komponen kursi }\end{array}$ & 3 & 4 \\
\hline 9. & $\begin{array}{l}\text { Jumlah kaki } \\
\text { kursi }\end{array}$ & 4 & 4 \\
\hline 10. & Jenis material & 4 & 2 \\
\hline 11. & $\begin{array}{l}\text { Diameter } \\
\text { material }\end{array}$ & 4 & 2 \\
\hline
\end{tabular}

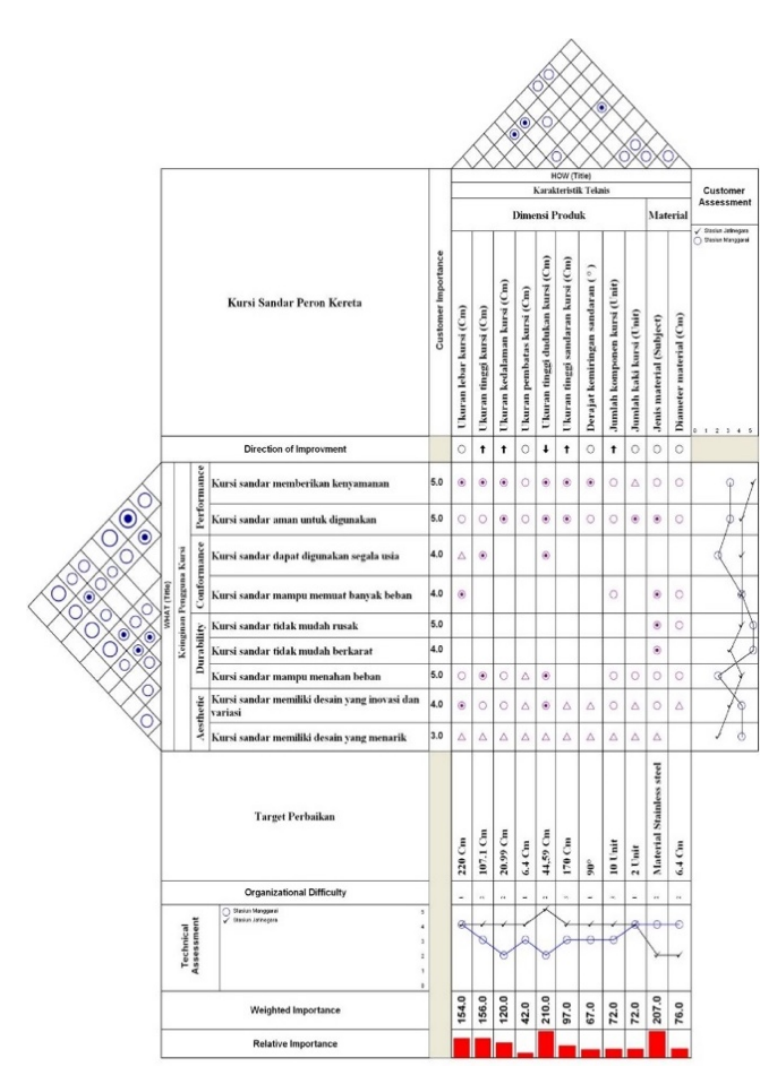

Gambar 5 House of quality 1 kursi sandar 


\section{Analisis Hasil}

Berdasarkan hasil keluaran rumah kualitas, didapatkan hasil weighted importance dan relative importante tertinggi sebesar 210,0. Prioritas yang dianggap penting oleh pengguna jasa untuk diwujudkan sebagai perbaikan pada produk kursi sandar yaitu pada tinggi dudukan kursi sandar. Rancangan yang ergonomis dapat dilihat dari kursi sandar yang memberikan kenyamanan dan kemananan bagi semua pengguna. Berdasarkan hasil keinginan pengguna jasa yang sangat penting untuk kursi sandar selain kenyamanan dan keamanan, rancangan kursi sandar perlu untuk mengaplikasikan kursi sandar yang tidak mudah rusak dan kursi sandar yang mampu menahan beban. Hal tersebut merupakan wujud dari rancangan kursi yang tidak menyebabkan kelelahan pada saat menggunakannya dan kursi yang mampu meminimalkan pengeluaran biaya pada waktu perawatan fasilitas. Kelelahan dapat mengganggu dari segi kesehatan, sedangkan kursi memiliki fungsi sebagai penghilang rasa lelah. Kursi yang tidak mudah rusak dapat digunakan oleh segala jenis ukuran tubuh pengguna jasa dan minim akan kerusakan besar yang mewajibkan perawatan yang ekstra.

\section{SIMPULAN} yaitu:

Simpulan dari penelitian ini anatra lain

1. Terdapat 9 atribut kebutuhan pengguna antara lain yaitu kursi sandar memberikan kenyamanan, kursi sandar aman untuk digunakan, kursi sandar dapat digunakan segala usia, kursi sandar mampu memuat banyak beban, kursi sandar tidak mudah rusak, kursi sandar tidak mudah berkarat, kursi sandar mampu menahan beban, kursi sandar memiliki desain yang inovasi dan variasi serta kursi sandar memiliki desain yang menarik.

2. Karakteristik teknis dominan berdasarkan hasil HOQ 1 yaitu ukuran tinggi dudukan kursi dan jenis material yang digunakan pada kursi sandar.
3. Perbaikan kursi sandar antara lain mengganti ukuran tinggi kursi, ukuran tinggi dudukan kursi, tinggi sandaran kursi, dan banyaknya jumlah kursi di peron stasiun.

4.

\section{DAFTAR PUSTAKA}

Cohen, Lou. 1995. Quality Function Deployment: How To Make QFD Work for You. New York: Addison-Wesley Publishing Company.

Jogiyanto. 2008. Metodologi Penelitian Sistem Informasi. Yogyakarta: CV. Andi Offset.

Kotler, Philip. 2006. Manajemen Pemasaran Edisi 11. Jakarta: PT. Indeks.

Kusuma, Edward Febriyatri. Kursi Di Peron Stasiun Manggarai Berubah Penumpang Commuter Line Mengeluh. https://m.detik.com/news/berita/d3043492/kursi-di-peron-stasiunmanggarai-berubah-penumpangcommuter-line-mengeluh. Diunggah pada tanggal 13 Oktober 2015.

Putra, Erik Purnama. Menuju Wajah Baru Stasiun Manggarai. https://www.republika.co.id/berita/ko ran/urbana/16/11/28/ohcmk216menuju-wajah-baru-stasiun-manggarai. Diunggah pada tanggal 28 November 2016.

Tjiptono, Fandy. 2008. Strategi Pemasaran, Edisi Tiga. Jakarta: Andi.

Umar, Husein. 2003. Metode Riset Bisnis. Jakarta: PT. Gramedia Pustaka Utama.

Walpole, R. E. 1992. Pengantar Statistika, Edisi Ketiga. Jakarta: Gramedia Pustaka Utama.

Wardani, Agustin Setyo. Setiap Stasiun Akan Dibangun Tempat Sandar Untuk Tunggu Penumpang.

http://wartakota.tribunnews.com/2015 /10/20/setiap-stasiun-akan-dibanguntempat-sandar-untuk-tunggupenumpang. Diunggah pada tanggal 20 Oktober 2015 